\title{
Familial glaucoma with sleep apnoea: a new syndrome?
}

\author{
JOHN T WALSH, JACQUES MONTPLAISIR
}

\author{
From the Centre d'étude du sommeil, Hôpital du Sacré-Coeur, Montréal, Québec, Canada
}

\begin{abstract}
Sleep apnoea was combined with glaucoma in five members of two generations of a family. The three surviving members with heavy snoring and glaucoma with intraocular pressure maxima in the morning and a fourth with heavy snoring only all had clinical sleep apnoea. The more severe glaucoma, resistant to surgery and medication, correlated with a greater number and duration of episodes of sleep apnoea. In all those who had recordings made episodes of sleep apnoea tended to occur and be more prolonged in rapid-eye-movement sleep. Oxygen desaturation was greater in rapid-eye-movement sleep and could occur without evidence of impaired respiration. In the third generation of this family there is as yet no evidence of impaired respiration in sleep or of glaucoma.
\end{abstract}

Genetic links have been amply documented for openangle glaucoma. ${ }^{1-3}$ According to current prevailing opinion, a tendency to glaucoma is not inherited as a simple Mendelian dominant or recessive trait but requires the interaction of several genes. ${ }^{4}$ Intraocular pressure is influenced by changes in heartbeat, respiration, and body position and is reduced by exercise, eating, alcohol, marijuana, stimulants, depressants, and some hormones. It may be increased by fluid intake, a rise in venous pressure, or release of prostaglandins within the eye. Intraocular pressure may vary in the course of the day, from one day to the next, with age, and with sex..$^{5}$

The genetics of the sleep apnoea syndrome is not yet understood ${ }^{6-8}$, and no cases of familial sleep apnoea syndrome combined with glaucoma have yet been recorded. The series of cases reported here extends the sparse literature of familial apnoea and has a bearing on the understanding of possible genetic factors contributing to glaucoma.

Early morning maxima for intraocular pressure are not uncommon, ${ }^{910}$ though their more usual occurrence is later in the day. A conjunction of early-morning peaks and declining intraocular pressure in conjunction with apnoea is noteworthy, particularly since sleep apnoea of clinical severity may be more common than hitherto suspected. ${ }^{11}$

Our investigation was initiated because one member of a family with a history of glaucoma had thought, from what he had learned about sleep disorders, that the early

Address for reprint requests: Dr John T Walsh, Centre d'étude du sommeil, Hôpital du Sacré-Coeur, 5400 ouest boulevard Gouin, Montréal, Québec, Canada H4J IC5. morning rise in his intraocular pressure might be related to some (then unknown) abnormality in his sleep. An initial interview with this patient (case 1) established a personal and family history of glaucoma and heavy snoring in several members of two generations.

\section{Methods}

Information about three generations of this family was obtained by personal interview, telephone, and letter and from physicians' reports. Questionnaires were returned by seven of eight surviving members of the second generation (fig 1), which provided data about glaucoma, snoring, somnolence, blood pressure, and personal history. An eighth member, who works as a missionary in a remote hamlet of Brazil, did not reply, though some information about her was furnished by other family members.

Four members of the second generation were studied in our laboratory for a total of 14 nights. Recordings included standard leads for sleep evaluation - electrocardiogram, oculogram, and myogram. There were strain-gauge leads for thoracoabdominal movement, thermistor recording of nasobuccal ventilation, and in two cases ear oximetry. Sleep recordings were scored, according to the criteria of Rechtschaffen and Kales, ${ }^{12}$ for sleep stages; and the criterion for apnoea was a duration of 10 seconds $^{10}$ and for oxygen desaturation $4 \%$ or more. ${ }^{11}$ Audiovisual monitoring by blacklight, temporally co-ordinated with the polygraph tracing, was maintained throughout. Polygraph data were evaluated by a computer program designed to correlate, quantify, and analyse sleep stages, apnoea, and desaturation. 
Results

FAMILY HISTORY

A family genealogy is shown in figure 1 . The mother (first generation) had had three operations for glaucoma in her 50s, snored heavily, had systemic hypertension, and died nearly blind at the age of 78 . Information obtained from a surviving member indicated that there was no other "eye trouble" in this generation. There was no other information on snoring or intermittent breathing in this first generation. There were nine siblings in the second generation, eight of whom survive. In 1970 the youngest was killed in a car accident. He had been diagnosed as having glaucoma with morning maxima and was subject to periodic breathing at night - "with non-breathing episodes and gasping," according to family members with whom we spoke. Five of the surviving siblings are snorers; three of them have glaucoma with early morning maxima (table 1 ).

There are nine members of the third generation, whose ages range from 5 to 33 years. None shows notable snoring or glaucoma at present. There have been no still-
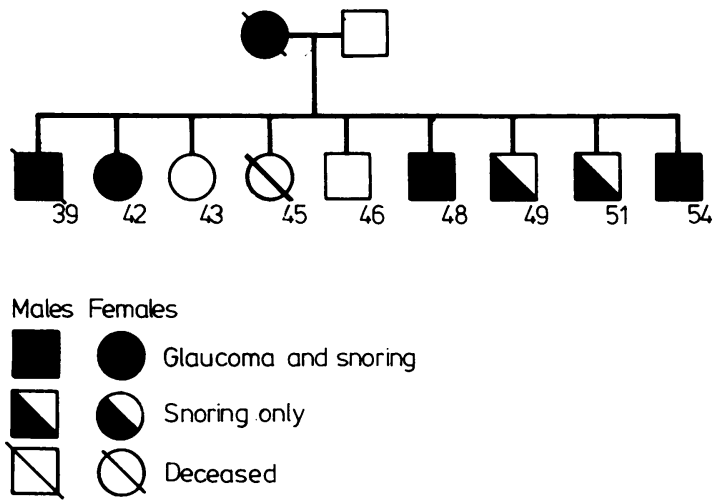

Fig 1 Genetic chart illustrating the distribution of heavy snoring and glaucoma in two generations. The third generation (not shown) has as yet no sign of glaucoma or impaired respiration in sleep. births or sudden infant deaths in this generation. Four of $\overline{\bar{N}}$ the second generation (including the three with glaucoma and one with heavier snoring) have been evaluated in our clinic and recordings have been made on them for a total of 14 nights.

Under ideal circumstances, we would have wished to do a complete study on all members of the second and third generations. The fact that the family was dispersed throughout north-east Canada, however, and that some $\vec{\omega}$ members did not wish to participate, made this impossible.

Case 1 This patient (age 48) has been treated for glaucoma since the age of 32 . He had surgery on his right eye in 1966 and received medication, but his intraocular $\vec{\overrightarrow{ }}$ pressure has remained raised. On several occasions his $\infty$ intraocular pressure, when it was measured at two-hour $\mathrm{or}$ intervals during waking hours, was at a maximum at $06.00 \mathrm{~h}$, declining thereafter in the course of the $\vec{Z}$ morning. Although he has not been treated for high 2 blood pressure, he has shown notably raised diastolic $\mathbb{D}$ levels on a number of occasions (140/115 and 160/130 $\mathrm{mm} \mathrm{Hg}$ ). In a recent telephone communication he in- $\mathbb{C}$ formed us that his blood pressure is now consistently $\vec{\omega}$ raised.

He averaged 418 episodes of apnoea a night with a mean duration of 25 seconds (fig 2). There was a tendency for the duration of these to increase if a given series was not interrupted by more prolonged waking. Apnoea was rare or absent in delta-wave stages of sleep. The obstructive nature of the apnoea was evident. Thoracoabdominal movements continued and in- $\overline{\overline{0}}$ creased in the course of the apnoea until respiratory 3 effort or a shift in stage achieved passage of air. Loud $\vec{F}$ breath sounds and visible labouring paralleled this pattern. The silence with the cessation of airflow would end with loud, sometimes explosive, snoring and rapid, deep respiratory movements. The patient does not com- $\vec{x}$ plain of daytime somnolence and has an active working life.

Case 2 This man (age 54) has had glaucoma since the $\stackrel{\mathrm{g}}{3}$

Distribution of sleep apnoea by sleep stages: average number, frequency, and duration of apnoeic episodes perpatient pernight, for all $\mathrm{O}$ nights recorded, in relation to each sleep stage

\begin{tabular}{|c|c|c|c|c|c|c|c|c|c|c|c|c|}
\hline \multirow{2}{*}{$\begin{array}{l}\text { Case No: } \\
\text { Sleep stages }\end{array}$} & \multicolumn{3}{|l|}{1} & \multicolumn{3}{|l|}{2} & \multicolumn{3}{|l|}{3} & \multicolumn{3}{|l|}{4} \\
\hline & No & $F^{*}$ & Dur & No & $F^{*}$ & Dur & No & $F^{*}$ & Dur & No & $F^{*}$ & Dur \\
\hline $\begin{array}{l}0 \\
1 \\
2 \\
3 \text { and } 4 \\
\text { REM } \\
\text { Total }\end{array}$ & $\begin{array}{r}15 \\
128 \\
229 \\
1 \\
45 \\
418\end{array}$ & $\begin{array}{c}12 \\
9 \\
0 \cdot 2 \\
10 \\
10 \cdot 1\end{array}$ & $\begin{array}{l}12 \\
23 \\
28 \\
20 \\
35\end{array}$ & $\begin{array}{r}3 \\
53 \\
48 \\
1 \\
32 \\
137\end{array}$ & $\begin{array}{l}7.6 \\
2.1 \\
0.3 \\
8.3 \\
3.7\end{array}$ & $\begin{array}{l}12 \\
17 \\
15 \\
12 \\
19\end{array}$ & $\begin{array}{r}0 \\
1 \\
24 \\
1 \\
18 \\
44\end{array}$ & $\begin{array}{l}0.5 \\
1.2 \\
0.2 \\
1.3 \\
1.4\end{array}$ & $\begin{array}{r}0 \\
11 \\
12 \\
12 \\
14\end{array}$ & $\begin{array}{r}0 \\
4 \\
14 \\
0 \\
13 \\
31\end{array}$ & $\begin{array}{l}1.0 \\
0.7 \\
\\
2.8 \\
1.0\end{array}$ & $\begin{array}{l}0 \\
15 \\
16 \\
0 \\
23\end{array}$ \\
\hline $\begin{array}{l}\text { Glaucoma } \\
\text { Surgery } \\
\text { Severity† }\end{array}$ & & $\begin{array}{c}\text { Right } \\
++\end{array}$ & & & $\begin{array}{r}\text { Right } \\
+\end{array}$ & & & & & & & \\
\hline
\end{tabular}

* Frequency: number of apnoeic episodes $/ 10$ min of sleep stage.

+ Severity of glaucoma: level of intraocular pressure and resistance to surgery and medication. 

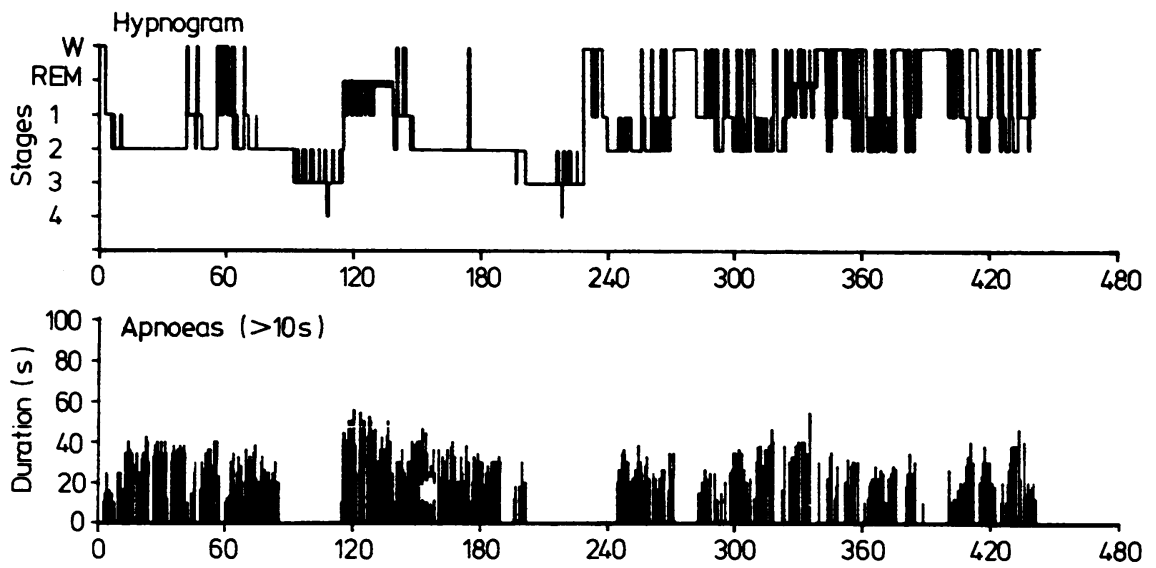

Fig 2 Distribution of apnoea and oxygen desaturation in relation to sleep stages in case 1, presenting with both periodic snoring and glaucoma.
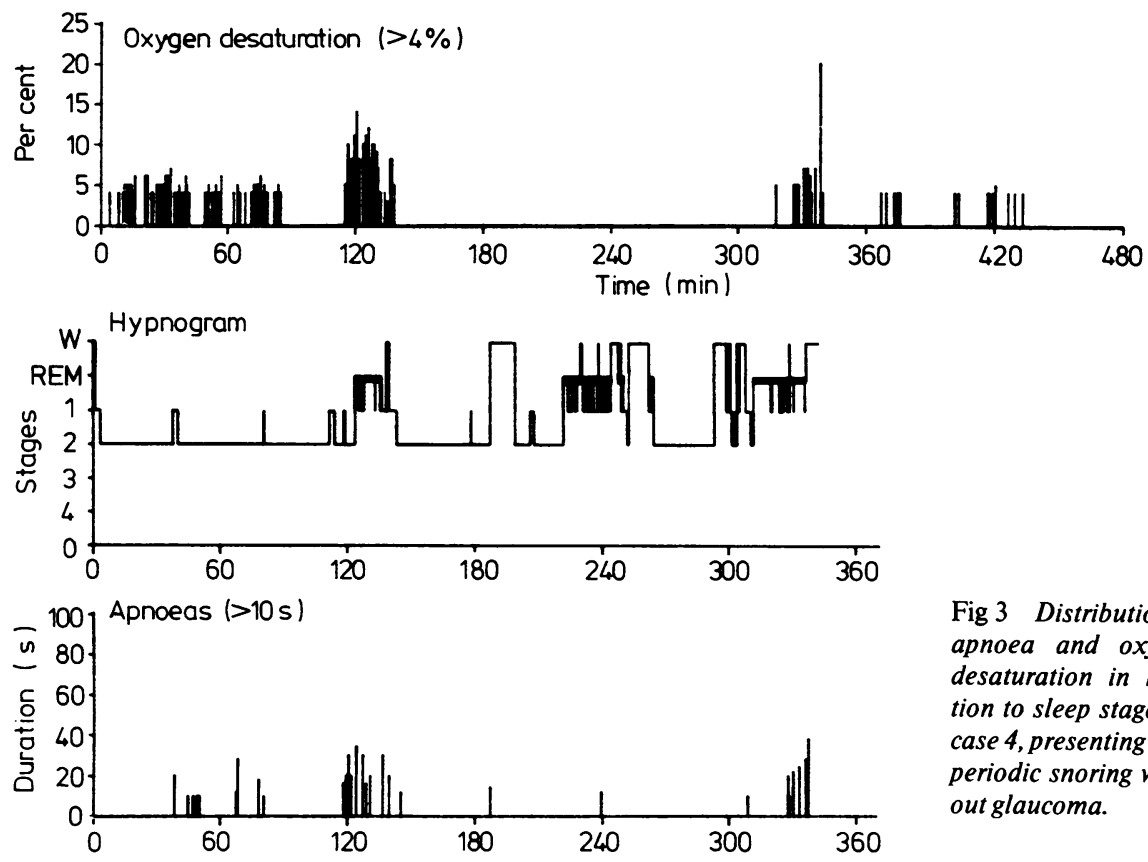

Fig 3 Distribution of apnoea and oxygen desaturation in relation to sleep stages in case 4, presenting with periodic snoring without glaucoma.

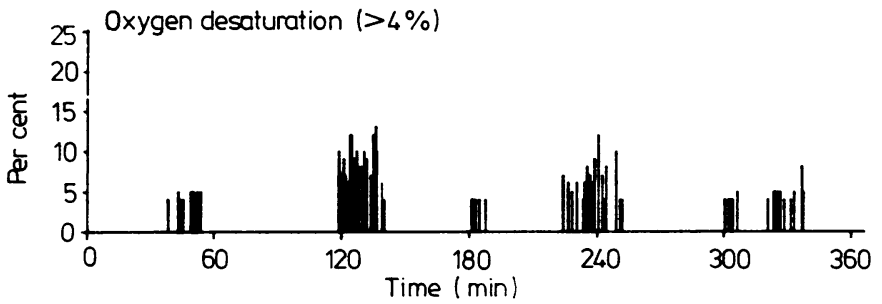

age of 39. Despite surgery on the right eye in 1968 and medication, his morning intraocular pressure remains raised. He has no other medical difficulties. He does not show any signs of hypertension, nor does he have daytime somnolence. Polygraphic recording over three nights showed an average of 137 apnoea episodes a night with a mean duration of 17 seconds. On the second night, when the number of episodes was considerably less (79) than on the other twothere were bouts of Cheyne-Stokes breathing. His apnoea was of the central type: respiratory movements and airflow diminished, increased, ceased, or resumed together. The episodes were rare or 
absent when delta waves were more abundant. Wakings and shifts of stage were frequent: in effect, every episode of apnoea or Cheyne-Stokes cycle led to a polygraphic shift, though this was often not long enough to qualify the epoch in which it occurred by standard criteria.

Case 3 This woman (age 42) has had glaucoma since the age of 26. Medication has been effective, though the intraocular pressure has remained somewhat raised, with early morning maxima. She has no other medical problems. She does not report daytime somnolence. Over three nights she averaged 44 episodes of apnoea a night with a mean duration of 12 seconds. Her breathing showed considerable irregularity and wakings were frequent. The apnoea was of the central type; her snoring was neither so loud nor so remarkable as that of the first two patients, and her sleep time was notably less (table 1) than theirs.

Case 4 This man (age 49) does not have glaucoma. He has been known to snore, with intermittent silences, for the last five years. He has no medical problems of which he is aware and does not have any daytime somnolence. He was studied in our clinic for a single night, during which he had 32 episodes of apnoea with an average duration of 19 seconds (the longest was 38 seconds) and one eight-minute bout of Cheyne-Stokes breathing. He had 67 episodes of oxygen desaturation, most of them during rapid-eye-movement (REM) sleep (fig.3). Three that exceeded $10 \%$ occurred in the absence of any apparent change in his ventilation or respiratory movements (fig 3). His episodes of apnoea were mixed: at times they were predominantly obstructive, at times predominantly central.

In all four patients apnoea was of longer duration in REM sleep; and where oximetry was used oxygen desaturation was seen to be more pronounced in REM sleep.

\section{Discussion}

The respiratory abnormalities of the cases reported here are generally consistent with published observations. Apnoea and oxygen desaturation were rare or absent in sleep stages 3 and 4, occured more in REM sleep, and showed a tendency to increase in duration when there was a long series in stage 2 . The fact that the apnoea presented a "spectrum" from central to obstructive supports the observations of Kurtz and Krieger ${ }^{13}$ on the difficulties and perhaps the futility of classifying patients according to the type of their sleep apnoea. Although in all likelihood some common genetic error is involved in all four, the ways in which the impaired respiratory function manifests itself differs.

Increases in oxygen desaturation and in the duration of apnoea in REM sleep may perhaps be explained by a combination of factors. Phillipson described a decreased ventilatory response to carbon dioxide during REM sleep and noted the arousal threshold in response to hypoxia to be considerably higher in REM sleep $(70.5 \%)$ than in slow-wave sleep (87.5\%). He also observed that few studies had been done on hypoxic responses during REM sleep in man. ${ }^{14} 15$

The absence of daytime somnolence in all our subjects is noteworthy. Although Dement et al note that "denial" is often a feature in such cases, ${ }^{16}$ the two severely affected patients spent two or more days in the laboratory between recording nights and there was no indication of somnolence. Both moreover lead active and successful lives. Why severe sleep apnoea leads to daytime somnolence in some but not in others remains to be explained. ${ }^{16} 17$ In the two severe cases observed here, possibly the sleep apnoea has had a very gradual onset that has permitted some physiological adaptation. In case 1 , for example, it is remarkable that during the second half of the night the episodes of apnoea produced few appreciable desaturations (fig 2). But to exclude completely the presence of excessive daytime sleepiness patients should be recorded during the day (multiple sleep latency test).

The sleep apnoea syndrome has not previously been implicated as a possible factor in the genesis of glaucoma or, more particularly, in glaucoma with a familial link. Evidently the physiological connection between the sleep apnoea syndrome and glaucoma requires further investigation. Of course, the two pathological conditions could be genetically related without one having an influence on the other. On the other hand, the fact that the two siblings whose sleep apnoea syndrome is the more severe also have more severe glaucoma at least suggests a connection. In cases 3 and 4 the possible relation is less persuasive, although the former patient, whose glaucoma is moderate, does show a slightly higher frequency than the latter(1.4 as compared with 1.0). Again, it would have been desirable to have studied both these patients for additional nights since our experience has been that the degree of respiratory impairment may vary considerably from one night to the next. Finally, the fact that the first three patients all show morning maxima at least suggests some relation between the sleep period and the rise of the intraocular pressure since, as already noted, such maxima, while not extraordinary, are less common at this time than later in the day.

In the absence of further evidence, we can only speculate about the ways in which sleep apnoea might occasion a rise in intraocular pressure. Changes in venous pressure cause an increase in the intraocular pressure $^{5}$ and fluctuations of intrathoracic pressure could thus play a direct role, although differences in this relation between "obstructive" and "central" apnoea are difficult to assess. Doubtless many changes could result from prolonged and repeated hypoventilation and hypoxaemia. But at present perhaps the most immed- 
iate concern should be attention to the possibility of increased intraocular pressure in sleep apnoea and of sleep apnoea in cases of glaucoma with intraocular pressure maxima in the early morning.

We are grateful to Dr J Dugré of Québec City for his help. The work was supported by grants from the Medical Research Council of Canada, and JM held a Scholarship of the Conseil de la recherche en santé du Québec.

\section{References}

${ }^{1}$ Armaly MF. Genetic determination of cup/disc ratios of the optic nerve. Arch Ophthal 1967;78:39-43.

${ }^{2}$ Bankes JKL, Perkins ES, Tsolakis S, Wright JE. Bedford glaucoma survey. $\mathrm{Br}$ Med J 1968;i:791-6.

${ }^{3}$ Graham PA. Epidemiology of simple glaucoma and ocular hypertension. BrJ Ophthalmol 1972;56:223-9.

${ }^{4}$ Schwartz JT, Reuling FH, Feinleib M, et al. Twin heritability study of the corticosteroid response. Trans Am Acad Ophthalmol Otolaryngol 1973;77:126-36.

${ }^{5}$ Worthen DM. Intraocular pressure and its diurnal variation. In: Heilman K, Richardson KT, eds. Glaucoma. Philadelphia: W B Saunders, 1978:54.

${ }^{6}$ Elliott J. Obstructive sleep apnea in a Georgia family: is it hereditary? JAMA 1978;240:2611.

${ }^{7}$ Strohl KP, Saunders NA, Feldman NT, Hallett M. Obstructive sleep apnea in family members. $N$ Engl J Med 1978;299:969-73.
${ }^{8}$ Goldberg R, Fish B, Ship A, Shprintzen RJ. Deletion of a portion of the long arm of chromosome 6. Am JMed Genet 1980;5:73-80.

${ }^{9}$ Drance SM. The significance of diurnal tension variations in normal and glaucomatous eyes. Arch Ophthalmol 1960;64:494-501.

${ }^{10}$ Kitazawa Y,Horie T. Diurnal variation of intraocular pressure in primary open angle glaucoma. Am J Ophthal 1975;79:557-66.

${ }^{11}$ Block AJ, Boysen PG, Wynne JW, Hunt LA. Sleep apnea, hypopnea and oxygen desaturation in normal subjects. $N$ Engl J Med 1979;300:513-7.

${ }^{12}$ Rechtschaffen A, Kales A (eds). A manual of standardized terminology, techniques and scoring system for sleep stages of human subjects. Los Angeles: University of California, 1968.

${ }^{13}$ Kurtz D, Krieger J. Analysis of apnea in sleep apnea. In: Guilleminault C, Dement WC, eds. Sleep apnea syndromes. New York: Alan R Liss Inc, 1978:145-59.

${ }^{14}$ Phillipson EA. Respiratory adaptation in sleep. Annu Rev Physiol 1978;40:133-56.

${ }^{15}$ Wynne JW, Block AJ, Hemenway J, Hunt LA, Flick MR. Disordered breathing and oxygen desaturation during sleep in patients with chronic obstructive lung disease (COLD). Am J Med 1979;66:573-9.

${ }^{16}$ Dement WC, Carskadon MA, Richardson G. Excessive daytime sleepiness in the sleep apnea syndrome. In: Guilleminault C, Dement WC, eds. Sleep apnea syndromes. New York: Alan R Liss Inc, 1978:23-46.

${ }^{17}$ Orr WC, Martin RJ, Imes NK, Rogers RM, Stahl ML. Hypersomnolent and nonhypersomnolent patients with upper airway obstruction during sleep. Chest 1979;75:418-22. 